\title{
O IMPACTO NA COMUNIDADE ACADÊMICA DO PROJETO DE EXTENSÃO DA UFJF - ENERGIAS RENOVÁVEIS NAS ESCOLAS
}

Luís Henrique Lopes Lima - luishenrique.lima@ufjf.edu.br

Universidade Federal de Juiz de Fora - UFJF, Faculdade de Engenharia

Rua José Lourenço Kelmer, s/n-Campus Universitário

Bairro São Pedro - CEP: 36036-900 - Juiz de Fora - MG

PabloCostaBastos-pablo.bastos@engenharia.ufjf.br

Universidade Federal de Juiz de Fora - UFJF, Faculdade de Engenharia

Rua José Lourenço Kelmer, s/n - Campus Universitário

Bairro São Pedro - CEP: 36036-900 - Juiz de Fora - MG

Resumo: Este artigo apresenta à comunidade acadêmica os resultados levantados acerca do projeto de extensão Energias Renováveis nas Escolas, vinculado a Universidade Federal de Juiz de Fora. O projeto consiste em apresentar aos alunos de escolas públicas e privadas, do ensino fundamental e médio, as alternativas limpas de geração de energia, como por exemplo as energias solar e eólica, sobre como é gerada a energia elétrica no Brasil atualmente e os novos modelos de geração que estão surgindo no mundo. Neste trabalho, explicitamos as formas encontradas pelos membros do projeto para driblar as dificuldades encontradas por eles encontradas, e os impactos causados pelo projeto nos discentes tanto da graduação quanto dos ensinos fundamental e médio.

Palavras-chave: Projeto de Extensão da UFJF; Energias renováveis; Escolas Públicas.

\section{INTRODUÇÃO}

O projeto de extensão Energias Renováveis nas Escolas, idealizado de acordocom as novas Diretrizes Curriculares Nacionais (DCNs) dos cursos de Engenharia pelo Ramo Estudantil do Instituto de Engenheiros Eletricistas e Eletrônicos (RE IEEE UFJF) vinculado a Universidade Federal de Juiz de Fora (UFJF), foi elaborado como uma forma de aproximar parte dos conhecimentos básicos adquiridos nas aulas teóricas e práticas da Faculdade de Engenharia aos alunos do ensino fundamental e médio de escolas da zona da mata mineira. (BRASIL, 2019)

O projeto conta, atualmente, com dois kits didáticos cedidos pelo Instituto de Engenheiros Eletricistas e Eletrônicos (IEEE), que são a base do projeto, e outros dois kits construídos, na Faculdade de Engenharia da UFJF, pelos membros do projeto. O kit didático de energia eólica é composto por um aerogerador em miniatura, apresentado na Figura 1, que carrega um carrinho de controle remoto quando este é acoplado ao aero gerador. Já o kit didático de energia solar é composto por pequenas placas solares que carregam, através de um carregador, o mesmo carrinho de controle remoto. Por fim, este kit didático também contém uma célula de eletrólise da água, como uma terceira fonte de geração de energia para ser explicada aos estudantes, como também apresentado na Figura 1. 
Figura 1 - Kits didáticos do projetoe a cidade inteligente em uma das apresentações
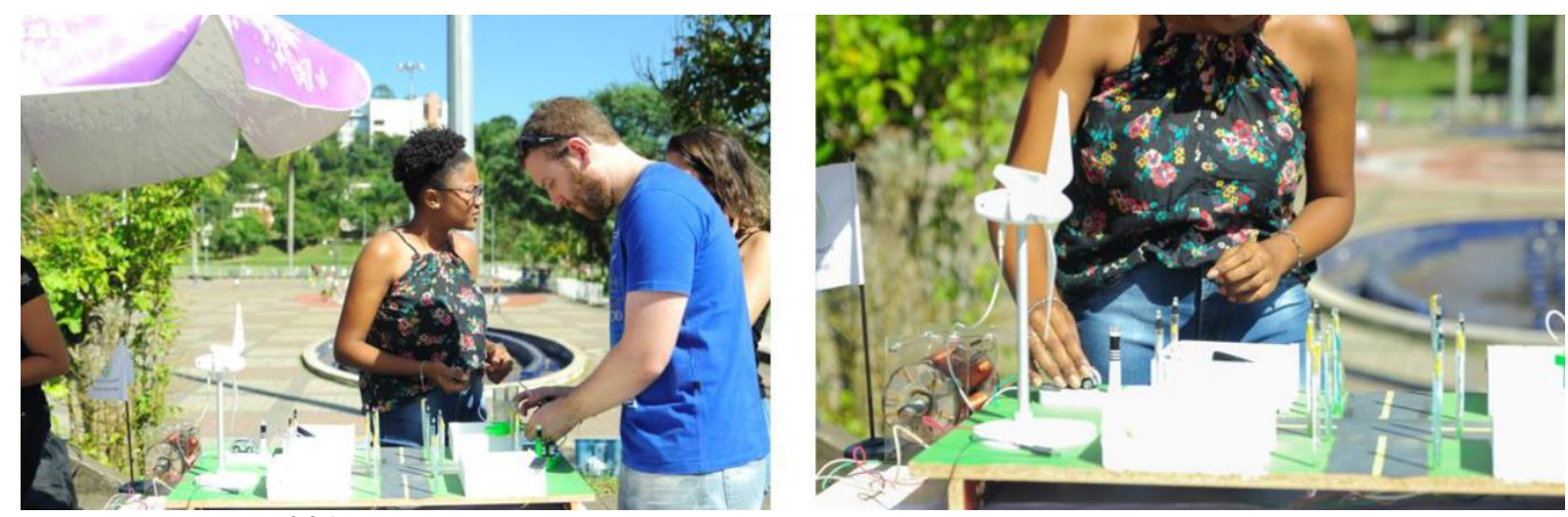

Fonte: UFJF, 2019.

Com o intuito de aumentar o alcance, tanto do tema quanto das escolas visitadas, os alunos que atuam como bolsistas do projeto de extensão desenvolveram um protótipo de cidade inteligente, apresentado na Figura 1, cujo intuito é mostrar com mais facilidade aos alunos do ensino fundamental e médio como as fontes renováveis seriam inseridas no contexto urbano. Esta cidade inteligente é composta por um aerogerador, simulando assim uma fonte eólica de geração de energia, e, também, um conjunto de placas fotovoltaicas que simulam a fonte solar distribuída de geração. Devido à complexidade do tema abordado, em algumas apresentações no ensino médio e abordando temas vistos nas aulas de Física, é levado, junto com estes kits, um gerador síncrono didático projetado pelos alunos do RE IEEE UFJF e construído com material reciclado. (PIRES; et al., 2019)

\section{O INÍCIO DO PROJETO DE EXTENSÃO}

\subsection{Motivação}

No início dos trabalhos do projeto de extensão, após algumas apresentações em escolas na cidade de Juiz de Fora/MG e região, notou-se que os alunos participantes não tinham um grande conhecimento a respeito dos temas abordados, alguns só conheciam esta tecnologia através de reportagens de jornais de repercussão nacional. Além disso, conversando posteriormente com os professores, se confirmou a fragilidade desses alunos em matérias associadas a área de exatas. Após algumas apresentações do projeto de extensão, nota-se uma melhora na atenção desses alunos o que evidencia o trabalho desse projeto como complemento ao ensino tradicional, pois é bastante interativo com os alunos e simula uma "aula prática" a respeito do tema abordado, facilitando, em geral, o aprendizado.

Em contato com professores, coordenadores de curso e diretores das escolas, percebe-se que boa parte das instituições não oferecem um espaço apropriado para a demonstração, de forma prática, dos conteúdos ensinados aos alunos na teoria dentro de sala de aula, a maioria dos espaços e laboratórios que existem são sucateados ou estão em condições bem precárias e não dão o suporte necessário para os professores trabalharem da forma que necessitam. 
"Os desafios para formar hoje o engenheiro do amanhã"

Tabela 1 - Disponibilida de percentual de recursos relacionados à infraestrutura nas escolas de ensino médio.

\begin{tabular}{|c|c|c|c|c|c|c|}
\hline \multirow{2}{*}{ Recurso } & \multicolumn{6}{|c|}{ DEPENDÊNCIA ADMINISTRATIVA } \\
\hline & Total & Pública & Federal & Estadual & Municipal & Privada \\
\hline Bib./sala de leitura & $87,5 \%$ & $85,7 \%$ & $98,1 \%$ & $85,4 \%$ & $82,7 \%$ & $91,9 \%$ \\
\hline Banheiro (dentro/fora) & $97,1 \%$ & $96,4 \%$ & $99,8 \%$ & $96,3 \%$ & $99,5 \%$ & $98,8 \%$ \\
\hline Banheiro PNE & $62,5 \%$ & $60,0 \%$ & $93,8 \%$ & $59,1 \%$ & $57,6 \%$ & $68,7 \%$ \\
\hline Dependências PNE & $46,8 \%$ & $44,3 \%$ & $79,5 \%$ & $43,4 \%$ & $37,7 \%$ & $52,7 \%$ \\
\hline Lab. de ciências & $44,1 \%$ & $38,8 \%$ & $83,4 \%$ & $37,5 \%$ & $28,8 \%$ & $57,2 \%$ \\
\hline Lab. de informática & $78,1 \%$ & $82,1 \%$ & $98,8 \%$ & $81,8 \%$ & $64,4 \%$ & $68,4 \%$ \\
\hline Internet & $95,1 \%$ & $93,6 \%$ & $99,3 \%$ & $93,5 \%$ & $85,9 \%$ & $98,7 \%$ \\
\hline Banda larga & $84,9 \%$ & $81,1 \%$ & $95,1 \%$ & $80,8 \%$ & $70,2 \%$ & $94,1 \%$ \\
\hline Pátio (cob./desc.) & $79,2 \%$ & $74,8 \%$ & $89,9 \%$ & $74,2 \%$ & $88,0 \%$ & $90,1 \%$ \\
\hline Quad. esp. (cob./desc.) & $75,9 \%$ & $72,8 \%$ & $70,0 \%$ & $72,8 \%$ & $73,3 \%$ & $83,6 \%$ \\
\hline
\end{tabular}

Fonte: INEP/Censo Escolar 2018

Pesquisando a realidade do Brasil em relação a esse tema, de acordocom a Tabela 1, apenas $44,1 \%$ das escolas têm acesso a laboratórios de ciências, se formos considerar apenas as escolas públicas, esse número diminui ainda mais, para 38,8\%. Em relação às escolas visitadas pelo projeto de extensão, $71 \%$ não possuem esses laboratórios. Se selecionarmos somente as escolas que ofertam disciplinas para o ensino médio, $57 \%$ das escolas possuem laboratório de ciências, enquanto $43 \%$ não os oferecem.

Em 2015, o Núcleo de Políticas Educacionais (NuPE) publicou um artigo intitulado "Utilização de Laboratórios Padrão MEC nas Escolas Estaduais do Paraná: o que dizem Estudantes e Professores", onde algumas escolas do estado do Paraná receberam um laboratório de ciências (biologia, química, física e matemática) enviados pelo Governo Federal com o objetivo de fazer um estudo sobre a utilização desses laboratórios e discutir sobre a utilização de aulas práticas na grade curricular dos alunos do ensino médio. Parte das respostas observadas pelos professores e alunos que fizeram parte deste artigo também foram observadas nas conversas realizadas nesse projeto de extensão. (JORGE; et al., 2015)

Aprofundando a conversa com os professores das escolas visitadas, a maioria sente dificuldade em relação à estrutura dos laboratórios, faltam insumos e principalmente, um professor ou técnico de apoio para uma melhor utilização do espaço, visto que as turmas são de aproximadamente 30 alunos, alguns materiais podem causar danos à saúde dos alunos, e que por falta de um técnico para auxiliá-los, não se sentem confortáveis em utilizar estes espaços. Alguns professores também não se sentem confortáveis em ministrar aulas nesses laboratórios, pois não possuem experiência prática nos temas abordados nesses espaços.

\section{SOLUÇÕES ENCONTRADAS PARA CONTORNAR AS DIFICULDADES}

No início do projeto, as apresentações eram realizadas com o uso de slides no computador e um projetor, porém em algumas escolas visitadas se observava que não era possível utilizar este tipo de material, então alguma adaptação precisava ser feita. Se percebia, também, que muitos alunos ainda não tinham conhecimento prévio a respeito do tema que se abordaria, pois mesmo com todo o material apresentado, ainda assim, não era suficiente para gerar o conhecimento que se gostaria. Então, alguma alteração na forma das apresentações deveria ser feita, principalmente, para facilitar o entendimento, em algumas nomenclaturas nos discursos para alunos do ensino fundamental $1\left(1^{\circ}\right.$ ao $5^{\circ}$ ano $)$, vide Figura 2. 
Figura 2 - Crianças a tentas diante da apresentação dos kits didáticos - a erogerador e eletrólise da á gua
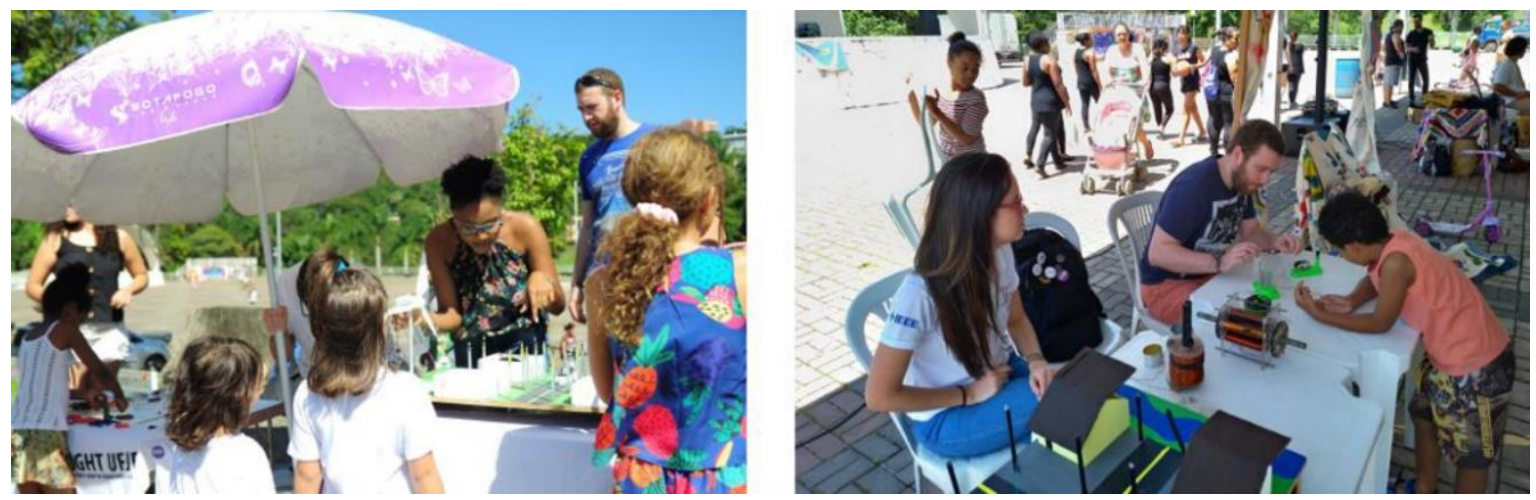

Fonte: UFJF, 2019.

Como não era só este o problema, os bolsistas do projeto de extensão começaram a desenvolver uma série de atividades para agregar ao que já se tinha. Sendo assim, resolveu desenvolver algumas atividades lúdicas para colorir e distribuir entre os alunos do ensino fundamental, como uma forma de complementar o aprendizado sobre o tema abordado nas apresentações, assim, eles podiam levar esses desenhos para suas casas e brincar com eles a posteriori, podendo replicar e desenhar novamente, conforme apresentado na Figura 3.

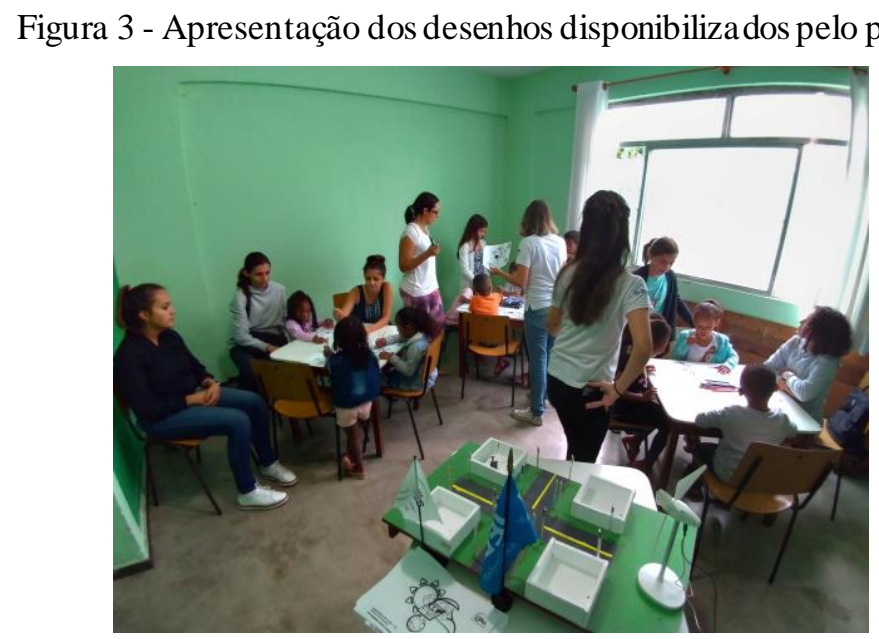

Fonte: Os a utores, 2019.

Não sendo suficiente, os bolsistas do projeto desenvolveram e construíram uma cidade inteligente para facilitar o entendimento do tema aos alunos do ensino fundamental $2\left(6^{\circ}\right.$ ao $9^{\circ}$ ano) e ensino médio, realizando as adaptações necessárias, de acordo com cada turma. $\mathrm{O}$ fato deste protótipo tornar mais visível a utilização de tecnologias de geração de energia renováveis, como eólica e fotovoltaica, deixa claro para estes alunos como ocorre a inserção destas novas tecnologias no sistema elétrico e no dia a dia de cada pessoa, seja ela utilizada para acender uma lâmpada de LED, seja ela para carregar um carro de controle remoto.

Para complementar, foi desenvolvido um gerador síncrono didático, como mostrado na Figura 4, para poder mostrar e explicar, de forma bem lúdica e simplificada, como ocorre a geração de energia elétrica em uma usina. Este protótipo foi construído, pelos alunos do RE IEEE UFJF, com materiais reutilizados de outros equipamentos, como por exemplo, os imãs de discos rígidos de antigos computadores. 
Figura 4 - Rea ção dos estudantes a ssistindo à a presentação do projeto - gera dor didático
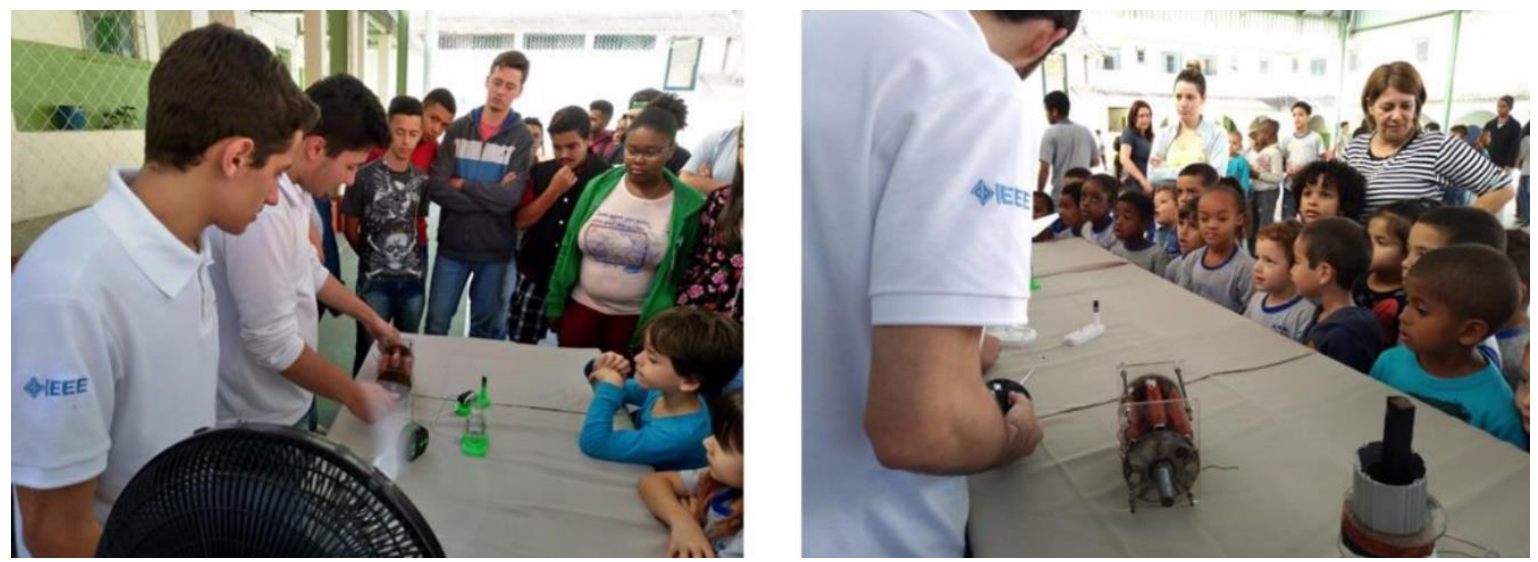

Fonte: Os autores, 2018.

Como se pode observar, o projeto de extensão foi implementado com a criação de novos kits para facilitar o entendimento do tema, que está de certo modo presente no nosso dia a dia, aos alunos do ensino fundamental e médio de escolas públicas e particulares.

\section{IMPACTOS DO PROJETO DE EXTENSÃO}

\subsection{Impactos nos estudantes das escolas atendidas}

Durante as apresentações, podemos perceber que pelo fato de a apresentação sobre o tema proposto ser mais lúdica e interativa, os estudantes demonstram maior interesse e curiosidade. Eles se sentem mais confortáveis para questionar o tema abordado nessas apresentações e se sentem entusiasmados a aprender mais sobre energias renováveis.

Tabela 2 - Relação das escolas visitadas entre out./2018 a dez./2019 e o número de estudantes atingidos.

\begin{tabular}{|c|c|c|}
\hline Escolas visitadas & Cidade/Estado & No de atingidos \\
\hline Escola Estadual Gov. Juscelino Kubitschek & Juiz de Fora/MG & 280 \\
\hline Escola Estadual Cornélia Ferreira Ladeira & Santos Dumont/MG & 300 \\
\hline Escola Municipal Quilombo dos Palmares & Juiz de Fora/MG & 200 \\
\hline Escola Municipal Engenheiro André Rebouças & Juiz de Fora/MG & 140 \\
\hline Colégio Stella Matutina & Juiz de Fora/MG & 75 \\
\hline Colégio de Aplicações João XXIII & Juiz de Fora/MG & 85 \\
\hline Escola Municipal Rocha Pombo & Juiz de Fora/MG & 145 \\
\hline Escola Estadual Chiquinho de Paiva & Capela Nova/MG & 260 \\
\hline Colégio de Aplicações João XXIII & Juiz de Fora/MG & 90 \\
\hline Escola Estadual Cornélia Ferreira Ladeira & Santos Dumont/MG & 300 \\
\hline Centro Educacional Saber é Viver & Juiz de Fora/MG & 75 \\
\hline
\end{tabular}

Fonte: Ramo Estudantil IEEE UFJF.

A partir dos dados da Tabela 2, podemos perceber que o número de estudantes atingidos é bem relevante, chegando a quase 2000 alunos do ensino fundamental e médio no período de um ano. Podemos perceber, também, que não é só no município de Juiz de Fora/MG, onde está situada a UFJF que acontecem as visitas do projeto de extensão. 
Diante do trabalho realizado pelos bolsistas do projeto podemos concluir que o aprendizado que foi repassado por eles aos estudantes das escolas visitadas pode proporcionar uma mudança de pensamento em relação ao tema de energias renováveis. Houve uma notória transformação no comportamento dos estudantes das escolas visitadas, e com isso, houve também uma mudança nos próprios bolsistas e voluntários que passaram a perceber o quão imp ortante é o trabalho desenvolvido pelo projeto. Poder incentivar pessoas a mudar seu pensamento, a se dedicar aos estudos, a ingressar em uma universidade pública ou mesmo particular, poder contribuir de forma positiva para estes estudantes é, no mínimo, contribuir para melhorar os profissionais que estes estudantes irão se tornar no futuro.

\subsection{Impactos nos bolsistas e voluntários do projeto de extensão}

Em razão dos obstáculos encontrados pelo projeto, se pode observar em nossos bolsistas e voluntários uma preocupação com o cenário encontrado por eles em relação ao conhecimento dos estudantes dos ensinos fundamental e médio a respeito do tema de energias renováveis. Houve uma grande e intensa pesquisa para poder elaborar os projetos adicionais que iriam ser integrados aos kits originais. Houve a preocupação de como trabalhar o vocabulário apresentado inicialmente para deixá-lo mais próximo do entendimento desses estudantes.

A busca pelo conhecimento na área de energias renováveis, visando a e laboração de projetos que possam ser incluídos no projeto de extensão, faz parte do processo de aprendizado desses voluntários, impactando, assim, na sua formação acadêmica. A troca de conhecimento afeta não só os estudantes das escolas visitadas, mas também os bolsistas e voluntários do projeto, que acabam adquirindo o conhecimento sobre o tema abordado com os seus colegas. $\mathrm{O}$ resultado desse trabalho, também pode ser visto nas figuras 5 e 6 .

Figura 5 - Energia eólica e cida de inteligente
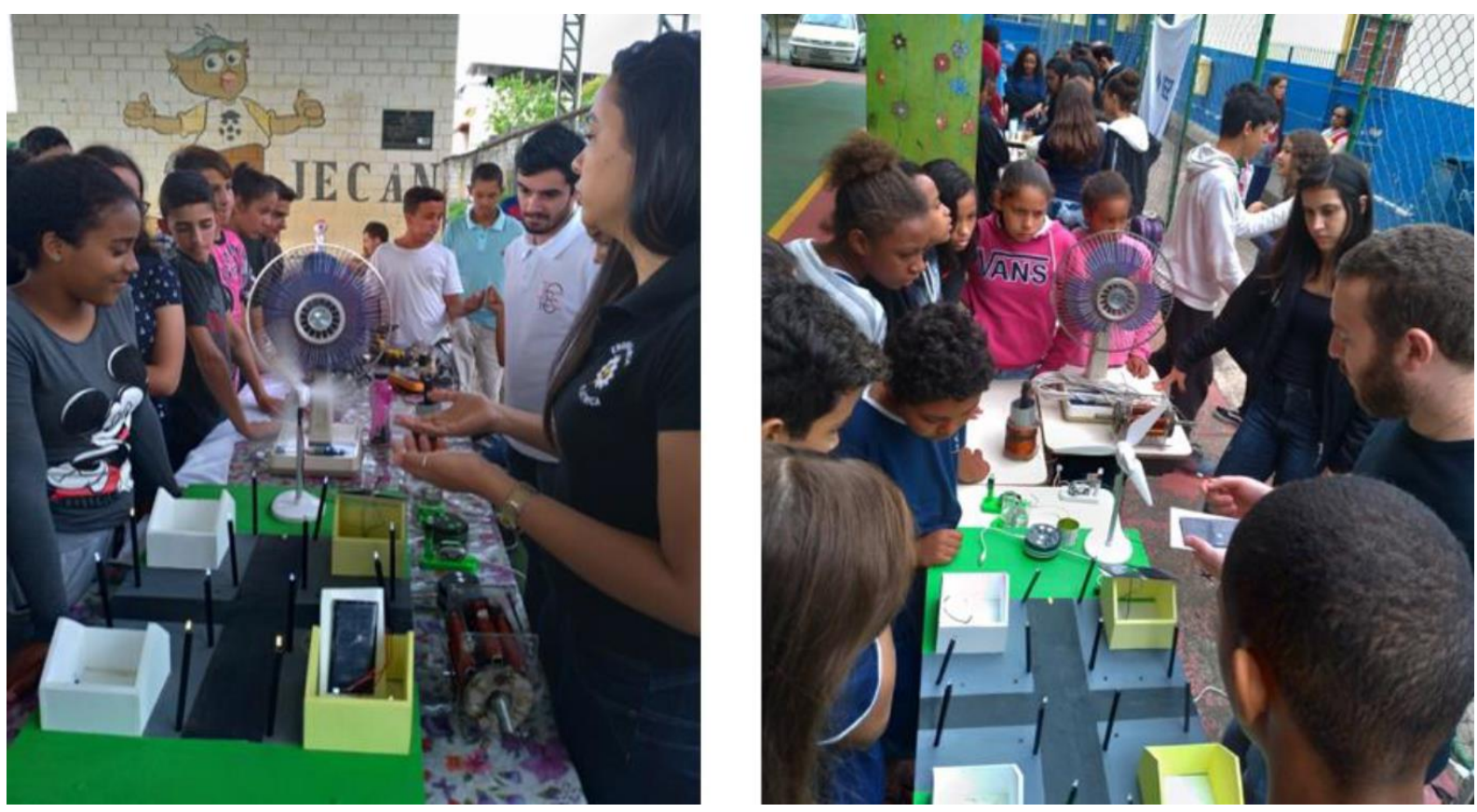

Fonte: Os autores, 2019. 
Figura 6 - Eletrólise da água

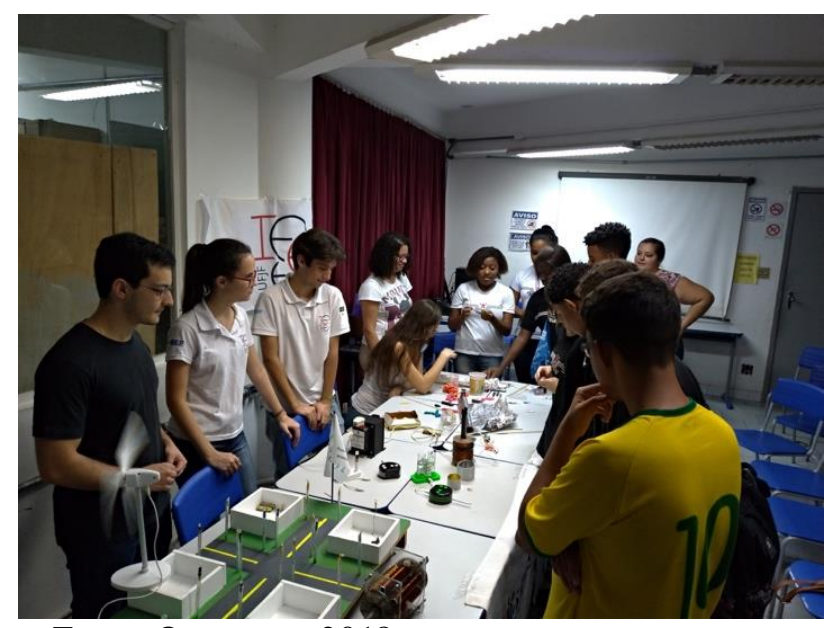

Fonte: Os a utores, 2018.

O resultado do trabalho, visto nos rostos dos estudantes, é um dos principais pontos apontados pelos bolsistas e voluntários como motivação para a continuação do trabalho nesse projeto. Isso marca a vida de uma pessoa, o fato de poder ensinar algo novo para alguém serve de motivação e inspiração para cada um deles, e afeta na sua busca para ser um engenheiro mais qualificado para o mercado de trabalho, e afeta ainda mais no ser humano por trás do engenheiro.

\section{CONSIDERAÇÕES FINAIS}

O fato de levar o conhecimento sobre um tema tão atual e importante, mostra o quão relevante é o trabalho realizado por este projeto de extensão da UFJF. O projeto proporciona aos estudantes do ensino fundamental e médio de escolas públicas e particulares uma aprendizagem fora do cotidiano das aulas tradicionais que, normalmente, tomam conta das salas de aula desses colégios, abordando o tema da energia elétrica de forma prática, e por isso os kits didáticos (gerador síncrono, placas fotovoltaicas, aerogerador e cidade inteligente) são extremamente importantes. Cada turma reage de maneira única ao que lhes é apresentado pelo projeto. É evidente nos rostos dos estudantes o impacto desse trabalho, e é gratificante, aos olhos dos bolsistas que pertencem ao projeto, poder ver as reações de alegria misturadas com espanto e curiosidade, tanto pelo conhecimento adquirido quanto pela parte visual.

Ao todo, quase 2000 estudantes foram atingidos diretamente pelo projeto, em 11 escolas visitadas durante o ano letivo de 2019. O impacto do trabalho na vida das pessoas envolvidas, tanto dos estudantes das escolas, quanto dos bolsistas pode ser visto em seus relatos de histórias e sorrisos ao se lembrarem do projeto e do conhecimento adquirido através dele, e essa é a marca deixada pelo projeto Energias Renováveis nas Escolas.

\section{Agradecimentos}

Gostaríamos de agradecer a Pró-reitora de Extensão da Universidade Federal de Juiz de Fora por todo apoio financeiro dado a este projeto de extensão antes e durante a sua execução; a todos os bolsistas e voluntários do projeto, que atuaram com muito carinho junto aos estudantes e a todos os profissionais da educação básica que nos receberam e cederam tempo e espaço para que pudéssemos realizar este trabalho tão importante. Muito obrigado!!! 


\title{
REFERÊNCIAS
}

BRASIL. Resolução n⿳2, de 24 de abril de 2019. Institui as Diretrizes Curriculares Nacionais do Curso de Graduação em Engenharia. Disponível em: http://www.in.gov.br. Acesso em: 20 mai. 2020.

INEP. Dados do Censo Escolar. Disponível em: http://bve.cibec.inep.gov.br/artigo. Acesso em: 25 mai. 2020.

INEP. Sinopse Estatística da Educação Básica 2018. Disponível em: http://download.inep.gov.br/informacoes_estatisticas/sinopses_estatisticas/sinopses_educacao _basica/sinopse_estatistica_da_educacao_basica_2018.zip. Acesso em: 25 mai. 2020 .

JORGE, C. M.; CECCATTO, A. P.; CAMPOS F. C.; JUNIOR C. V. T. Utilização dos laboratórios padrão MEC nas escolas estaduais do Paraná: o que dizemestudantes e professores. Jornal de Políticas Educacionais, Curitiba, v.9, n.17 e 18, p. 125-136, 2015.

PIRES, C. A. A.; SANTOS, J. L. C.; OLIVEIRA, J. G. de; LIMA, L. H. L. A Importância dos Trabalhos Realizados pelo Ramo Estudantil IEEE UFJF na Formação de Voluntários e no Desenvolvimento da Universidade. In: XLVII Congresso Brasileiro de Educação em Engenharia, 2019, Ceará. Anais eletrônicos. Fortaleza, 2019.

RAMO ESTUDANTIL IEEE UFJF. Potência e Energia. Disponível em: https://edu.ieee.org/br-ufjf/capitulos-tecnicos/pes. Acesso em 31 mai. 2020.

\section{THE IMPACT ON THE ACADEMIC COMMUNITY OF THE UFJF EXTENSION PROJECT - RENEWABLE ENERGIES IN SCHOOLS}

\begin{abstract}
This article presents to the academic community the results raised about the Renewable Energies in Schools extension project, linked to the Federal University of Juiz de Fora. The project consists of presenting to the students of public and private schools, of elementary and high school, the clean alternatives of energy generation, as for example the solar and wind energy, about how electric energy is generated in Brazil today and the new models generation that are emerging in the world. In this article, we explain the found methods by the members of the project to avoid the difficulties found, and the impacts caused by the project on students both in undergraduate college and in elementary and high school.
\end{abstract}

Keywords: Extension Project of UFJF, Renewable Energies, Publish Schools. 